\title{
TOMOGRAFIA COMPUTADORIZADA DE ALTA RESOLUC̣ÃO NAS COMPLICAÇÕES PULMONARES PÓS-TRANSPLANTE DE MEDULA ÓSSEA: ENSAIO ICONOGRÁFICO*
}

\author{
Emerson L. Gasparetto ${ }^{1}$, Sergio E. Ono ${ }^{1}$, Dante L. Escuissato ${ }^{2}$, Carolina A. Souza ${ }^{1}$, \\ Gabriela de Melo Rochaa ${ }^{3}$, Cezar Inoue ${ }^{3}$, João M. Falavigna ${ }^{3}$, Edson Marchiori ${ }^{4}$
}

Resumo 0 transplante de medula óssea (TMO) tem sido utilizado como tratamento de escolha para diversas doenças hematológicas. Entretanto, as complicações pulmonares, que podem ocorrer em até $60 \%$ dos pacientes, são o principal motivo de falha no tratamento. As complicações pulmonares pós-TMO podem ser divididas em três fases, de acordo com a imunidade do paciente. Na primeira fase, até 30 dias após o procedimento, predominam as complicações não infecciosas e as pneumonias fúngicas. Na fase precoce, que vai até o $100^{\circ}$ dia pós-TMO, as infecções virais, principalmente por citomegalovírus, são mais comuns. Finalmente, na fase tardia pós-TMO, complicações não infecciosas como bronquiolite obliterante com pneumonia em organização e doença do enxerto contra o hospedeiro são mais comumente observadas. Os autores apresentam um ensaio iconográfico, enfatizando os aspectos de tomografia de alta resolução em pacientes com complicações pulmonares pós-TMO.

Unitermos: Tomografia computadorizada de alta resolução; Transplante de medula óssea; Infecções pulmonares.

Abstract High-resolution computed tomography findings in pulmonary complications after bone marrow transplantation: iconographic essay.

Bone marrow transplantation has been the treatment of choice for many hematologic diseases. However, pulmonary complications, which may occur in up to $60 \%$ of the patients, are the main cause of treatment failure and may be divided in three phases according to the patient's immunity. In the first phase, up to 30 days after the procedure, there is a predominance of non-infectious complications and fungal pneumonia. Viral infections, mainly by cytomegalovirus, are common in the second phase (up to 100 days after bone marrow transplantation). Finally, in the late phase after bone marrow transplantation, non-infectious complications as bronchiolitis obliterans organizing pneumonia and graft-versus-host disease are most commonly seen. The authors present a pictorial essay of the high-resolution computed tomography findings in patients with pulmonary complications after bone marrow transplantation.

Key words: High-resolution computed tomography; Bone marrow transplantation; Pulmonary infections.

\section{INTRODUÇÃO}

O transplante de medula óssea (TMO) consiste na infusão intravenosa de células progenitoras hematopoiéticas para restabelecer a função da medula óssea, sendo que

\footnotetext{
* Trabalho realizado na Disciplina de Radiologia Médica do Departamento de Clínica Médica da Universidade Federal do Paraná (UFPR), Curitiba, PR.

1. Médicos Residentes do Serviço de Radiologia Médica Diagnóstico por Imagem do Hospital de Clínicas da UFPR.

2. Professor Assistente da Disciplina de Radiologia Médica da UFPR.

3. Acadêmicos de Medicina da UFPR.

4. Professor Titular de Radiologia da Universidade Federa Fluminense (UFF), Coordenador Adjunto do Curso de Pós-Graduação em Radiologia da Universidade Federal do Rio de Janeiro (UFR).

Endereço para correspondência: Dr. Emerson L. Gasparetto. Serviço de Radiologia Médica, Hospital de Clínicas da UFPR. Avenida General Carneiro, 181. Curitiba, PR, 80060-900. E-mail: gasparetto@hotmail.com

Recebido para publicação em 28/10/2004. Aceito, após re-
} visão, em 15/12/2004. este procedimento tem seu papel definido no tratamento de doenças hematológicas.

As principais complicações do TMO são a doença do enxerto contra hospedeiro (DECH) aguda ou crônica, a rejeição e as complicações pulmonares. As complicações pulmonares ocorrem em $40 \%$ a $60 \%$ dos pacientes submetidos ao $\mathrm{TMO}^{(1,2)} \mathrm{e}$ estão associadas a morbidade e mortalidade significativas.

A tomografia computadorizada de alta resolução (TCAR) é um excelente método para deteç̧ão de anormalidades pulmonares, porém deve ser ressaltado que os achados vistos na TCAR em geral são inespecíficos e necessitam de correlação clínica e temporal, baseada no estado imunológico do paciente ${ }^{(3)}$.

Neste estudo serão discutidas e ilustradas as TCAR das principais complicações pulmonares que ocorrem em pacientes submetidos a TMO.

O período pós-TMO é dividido em três fases (Figura 1):

- A primeira fase, também conhecida como neutropênica, compreende as três primeiras semanas pós-TMO e é caracterizada por infecções fúngicas, hemorragias alveolares, edema pulmonar e reações a drogas;

- a segunda fase, ou fase precoce, compreende o período entre a terceira semana e o $100^{\circ}$ dia pós-TMO, sendo comum nesta fase as infecções por citomegalovírus (CMV) e vírus sincicial respiratório (VSR);

- a terceira fase, ou fase tardia (após 100 dias pós-TMO), é caracterizada pela ocorrência de bronquiolite obliterante com pneumonia em organização (BOOP) e DECH crônica ${ }^{(2-4)}$. 


\section{FASE NEUTROPÊNICA}

$\mathrm{Na}$ fase imediatamente após o transplante há um período de neutropenia profunda que dura de duas a três semanas. As complicações pulmonares são predominantemente infecções fúngicas (mais comumente a aspergilose angioinvasiva), hemorragia alveolar difusa, edema pulmonar e toxicidade a drogas ${ }^{(3)}$.

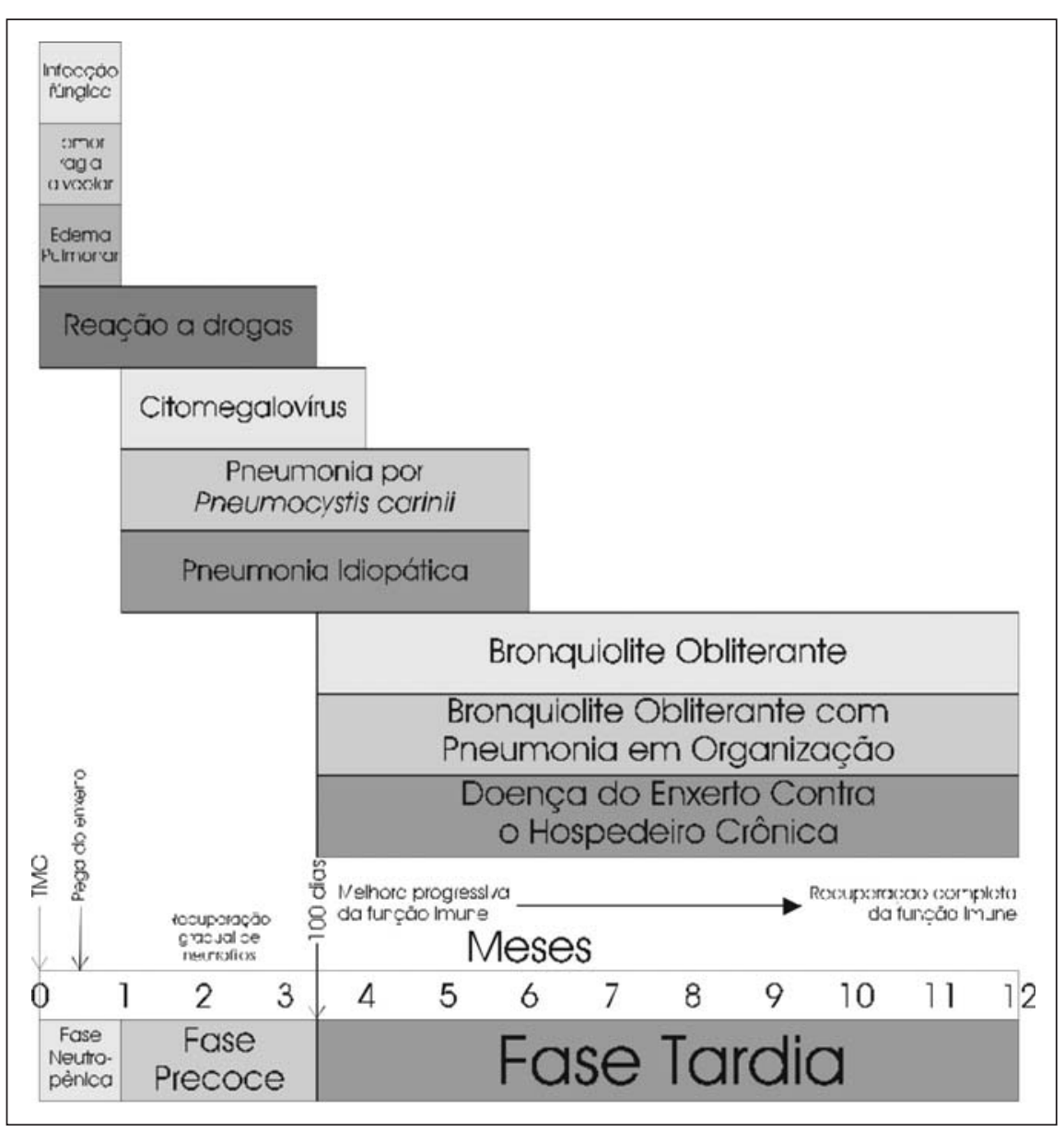

\section{Infecções fúngicas}

Os fungos são causa comum de pneumonia em pacientes pós-TMO, com incidência entre $12 \%$ e $45 \%$. O Aspergillus sp. é o fungo mais isolado no período pósTMO, sendo causa de pneumonia em até $20 \%$ dos pacientes ${ }^{(2)}$.

\section{Aspergilose invasiva}

Os fatores de risco desta infecção incluem granulocitopenia prolongada, uso de antibióticos de amplo espectro, lesão de mucosa e tratamento com corticosteróides. O diagnóstico pode ser feito por culturas positivas de tecido pulmonar obtido por biópsia percutânea, biópsia a céu aberto ou por autópsia.

Os achados radiográficos são variados, podendo ser observados infiltrações focais ou difusas, com ou sem escavações, nódulos, massas, ou a combinação de nódulos e massas ${ }^{(5,9}$. O principal achado no exame de TCAR é o de nódulo circundado por atenuação em vidro-fosco, conhecido como o sinal do halo ${ }^{(3)}$. A escavação do nódulo ocorre na fase de recuperação da neutropenia e aparece como o sinal do crescente aéreo. Pode ainda haver áreas de consolidação segmentar causadas por infarto pulmonar, devido à invasão vascular. A invasão de vias aéreas ocorre em $30 \%$ dos $\operatorname{casos}^{(7)}$, e anormalidades à TCAR incluem nódulos centrolobulares ou peribroncovasculares (Figuras 2 e 3 ).

Figura 1. Alterações do sistema imune e complicações pulmonares associadas no período pós-TMO.

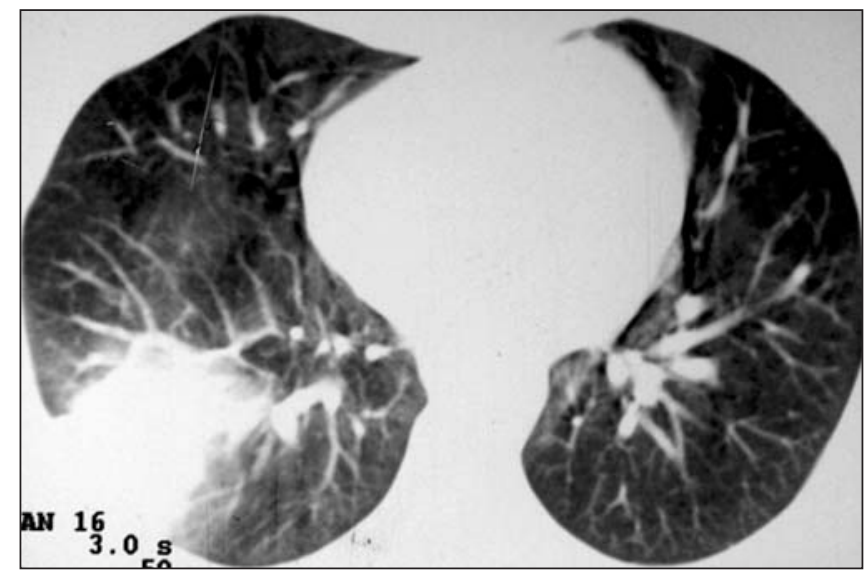

A

Figura 2. Corte de TCAR ao nível dos lobos inferiores demonstra massa periférica circundada por halo de vidro-fosco (sinal do halo) no lobo inferior direito, em paciente com diagnóstico de pneumonia por Aspergillus sp. (A). Na janela para mediastino notam-se impregnação periférica pelo meio de contraste iodado e área central hipodensa, que representava necrose (B).

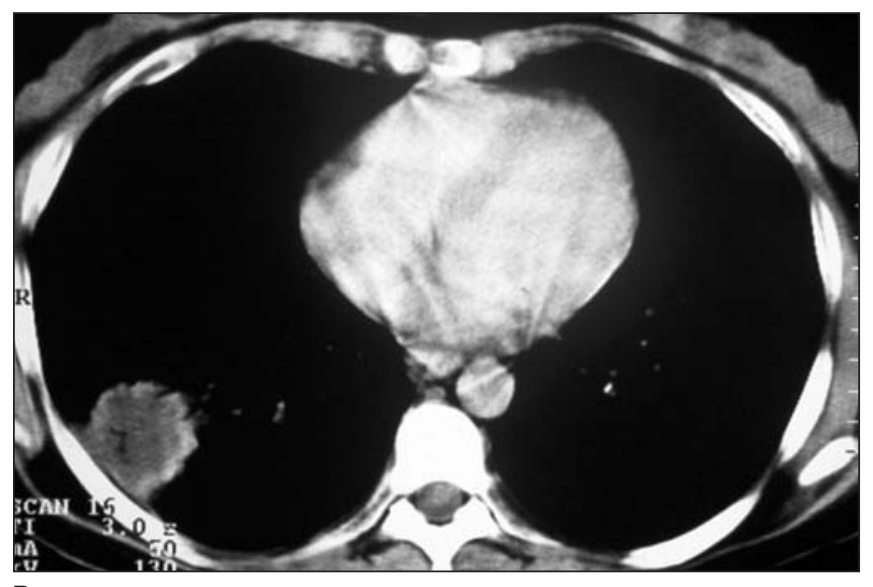

B 


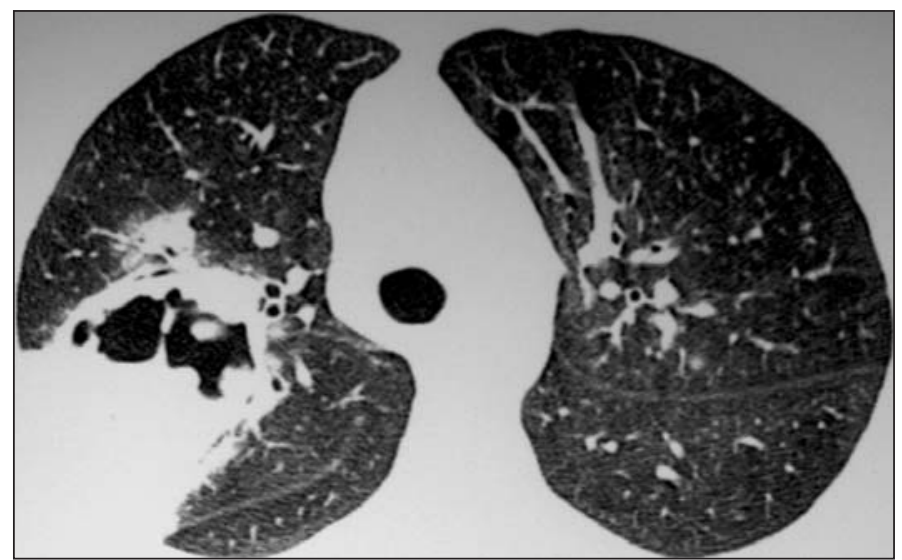

A

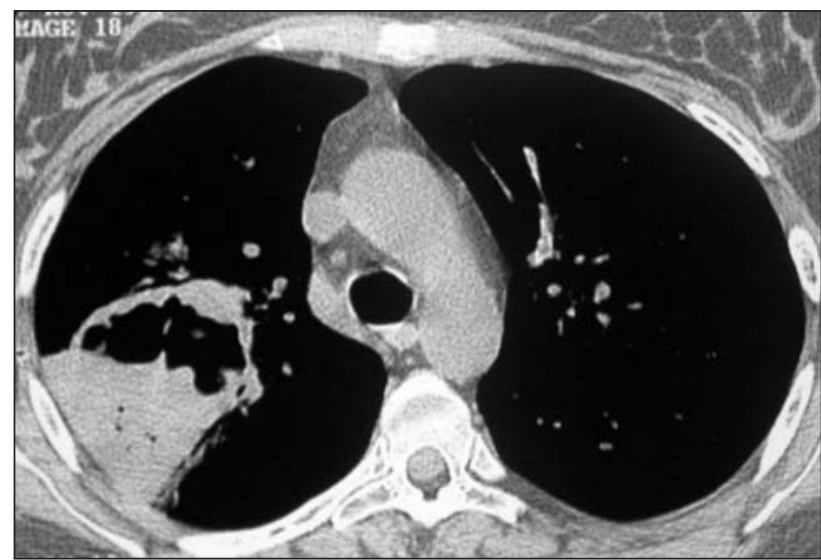

B

Figura 3. Corte de TCAR ao nível dos lobos superiores com janela para pulmão (A) e mediastino (B) revela área de consolidação escavada no lobo superior direito, com limites definidos, paredes irregulares, sem evidência de halo de vidro-fosco. 0 diagnóstico de aspergilose invasiva foi definido por biópsia a céu aberto.

\section{Infecções bacterianas}

São complicações comuns, ocorrendo em $20 \%$ a $50 \%$ dos pacientes, e correlacionam-se com o período de granulocitopenia antes da pega do enxerto. O grupo predominante é o de bactérias Gram-negativas, provenientes do trato gastrintestinal ou da mucosa oral ${ }^{(2)}$. O diagnóstico pode ser definido a partir de culturas do lavado broncoalveolar (LBA).

Os achados radiográficos e de TCAR não diferem daqueles observados em pacientes imunocompetentes com pneumonia bacteriana. A TCAR é útil no diagnóstico precoce desta infecção, quando as radiografias ainda são normais. Nesta fase a TCAR pode demonstrar áreas de atenuação em vidro-fosco, sugerindo o diagnóstico e a instituição terapêutica precoces (Figuras 4 e 5).

\section{Hemorragia alveolar difusa (HAD)}

A HAD ocorre em até $20 \%$ dos pacientes submetidos a TMO autólogo, e é diagnosticada entre o $7^{\circ}$ e $40^{\circ}$ dias pós-TMO (média D+12). É caracterizada por estabelecimento súbito de dispnéia progressiva, tosse não produtiva, febre e hipoxemia ${ }^{(2)}$. O LBA define o diagnóstico, evidenciando macrófagos contendo hemossiderina.

As radiografias de tórax demonstram consolidação difusa, geralmente envolvendo mais de um lobo. Os achados mais comuns na TCAR são áreas de atenuação em vidro-fosco bilaterais e consolidações ${ }^{(3)}$ (Figura 6).

\section{Edema pulmonar}

O edema pulmonar em geral ocorre na segunda ou terceira semana pós-TMO. Esta alteração resulta da infusão de grandes quantidades de fluidos para administração de drogas, produtos sanguíneos e nutrição parenteral total, combinada a disfunções cardíaca e renal, secundárias a quimioterapia e imunossupressão prévias ${ }^{(2)}$.

As anormalidades na radiografia de tórax incluem redistribuição vascular e aumento difuso da trama intersticial. As TCAR mostram vasos pulmonares proeminentes, espessamento de septos interlobulares, áreas de atenuação em vidro-fosco e derrame pleural $^{(3)}$ (Figura 7).

\section{Toxicidade a drogas}

Complicações pulmonares relacionadas a drogas citotóxicas são frequientes e podem ser potencializadas pela irradiação do parênquima pulmonar nos pacientes submetidos à irradiação corporal total no período pré-TMO. As principais drogas

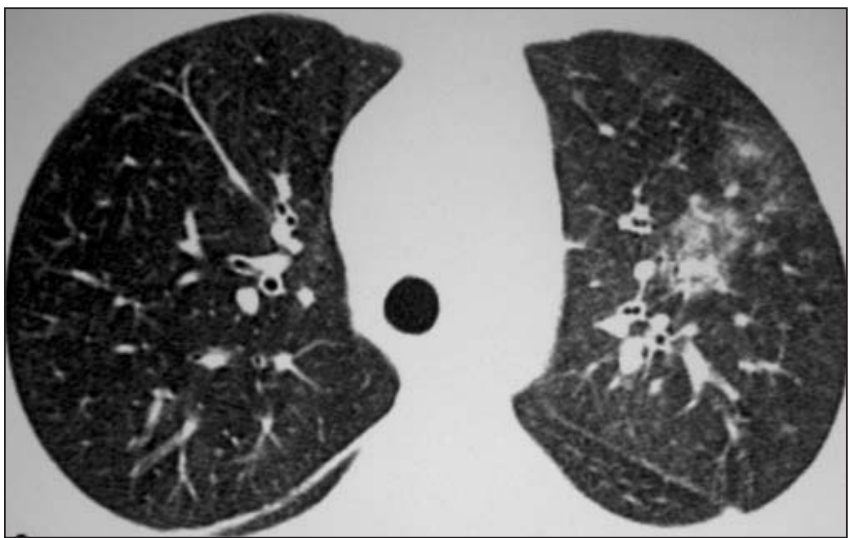

Figura 4. Corte de TCAR ao nível dos lobos superiores mostra áreas de atenuação em vidro-fosco esparsas no lobo superior esquerdo de um paciente com pneumonia por Staphylococcus aureus.

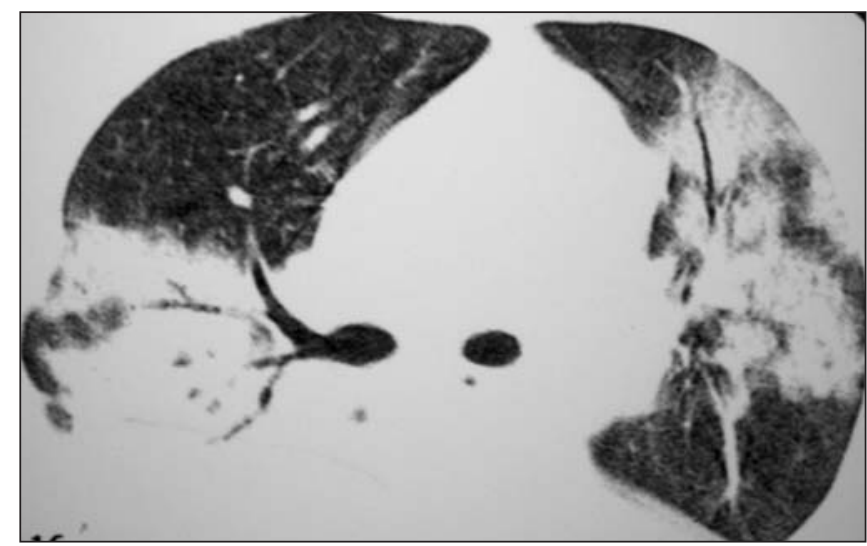

Figura 5. Corte de TCAR ao nível dos brônquios principais mostra consolidações bilaterais decorrentes de infecção por Streptococcus pneumoniae. 


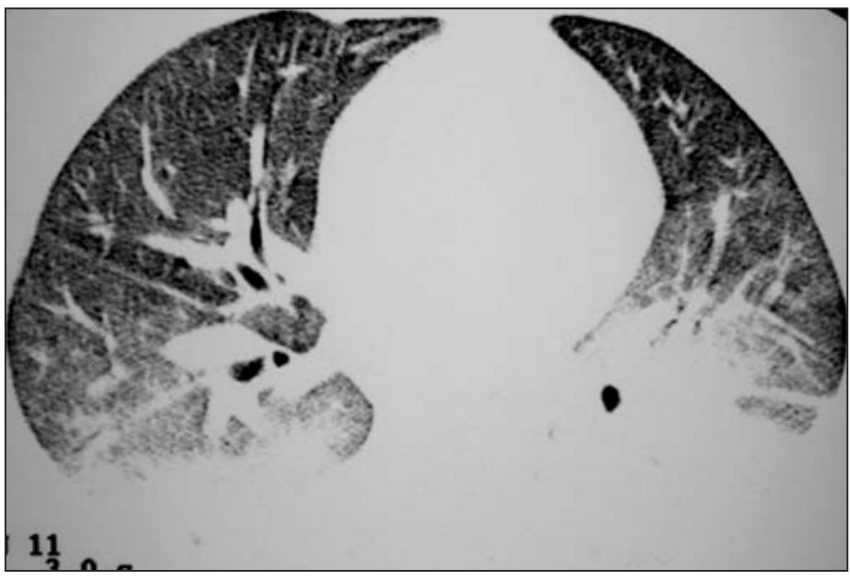

Figura 6. Corte de TCAR ao nível do lobo médio mostra áreas de consolidação nos segmentos superiores dos lobos inferiores e áreas de atenuação em vidrofosco nas regiões adjacentes. O diagnóstico de hemorragia alveolar difusa foi definido através de LBA.

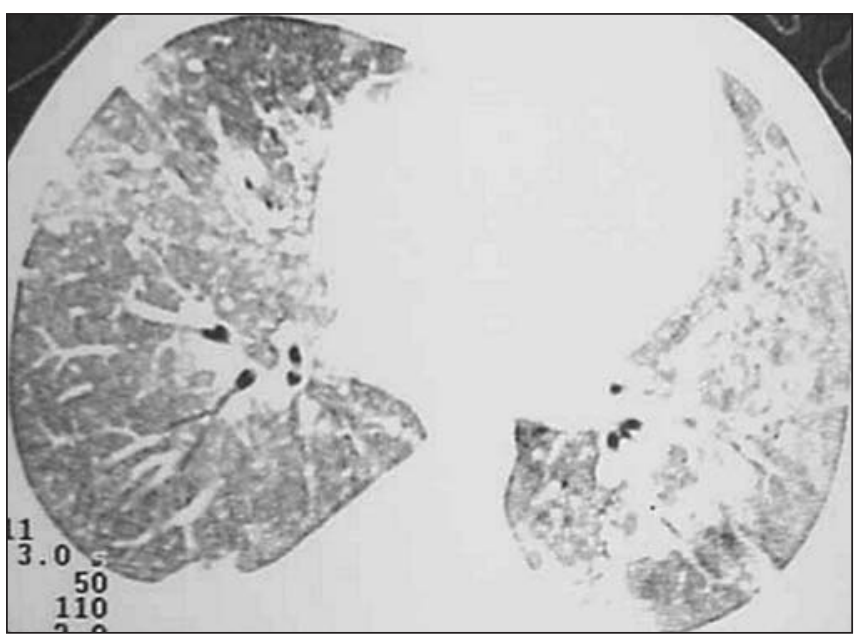

Figura 7. Corte de TCAR ao nível das pirâmides basais demonstra áreas de atenuação em vidro-fosco, focos de consolidação e proeminência da circulação pulmonar. 0 diagnóstico de edema agudo de pulmão foi definido no período da evolução. implicadas nesta complicação são bleomicina, bussulfan e metotrexate.

Os achados na TCAR são variados e inespecíficos, incluindo áreas de atenuação em vidro-fosco ${ }^{(7)}$, consolidações, ou em estágios mais tardios, áreas de infiltração intersticial reticular (Figura 8).

\section{FASE PRECOCE}

A próxima fase vai do dia 21 até os 100 dias pós-TMO, quando ocorre recuperação gradual dos neutrófilos e do sistema imune. Nesta fase predominam as infecções virais, sendo o CMV e o VSR os vírus com maior frequiência diagnosticados.

\section{Pneumonia por CMV}

A infecção pelo CMV ocorre em até $70 \%$ dos pacientes submetidos a TMO, sendo que um terço destes desenvolve pneumonia. Os sintomas iniciam entre $6 \mathrm{e}$ 12 semanas pós-TMO ${ }^{(7)}$. As características clínicas da pneumonia por CMV são febre, tosse não produtiva, dispnéia e hipoxemia. O diagnóstico pode ser feito por imunofluorescência indireta aplicada ao LBA. O diagnóstico histológico é confirmado pelo achado de macrófagos pulmonares contendo inclusões intranucleares típicas.

Os achados radiográficos incluem infiltração intersticial difusa, opacidades parenquimatosas e a presença de inúmeros pequenos nódulos. $\mathrm{O}$ aspecto mais comum na TCAR são pequenos nódulos associados a áreas de consolidação ou de atenuação em vidro-fosco ${ }^{(3,8)}$ (Figuras 9 e 10).

\section{Vírus sincicial respiratório}

Estudos recentes têm mostrado que vírus respiratórios da comunidade, como o VSR, influenza vírus, parainfluenza vírus,

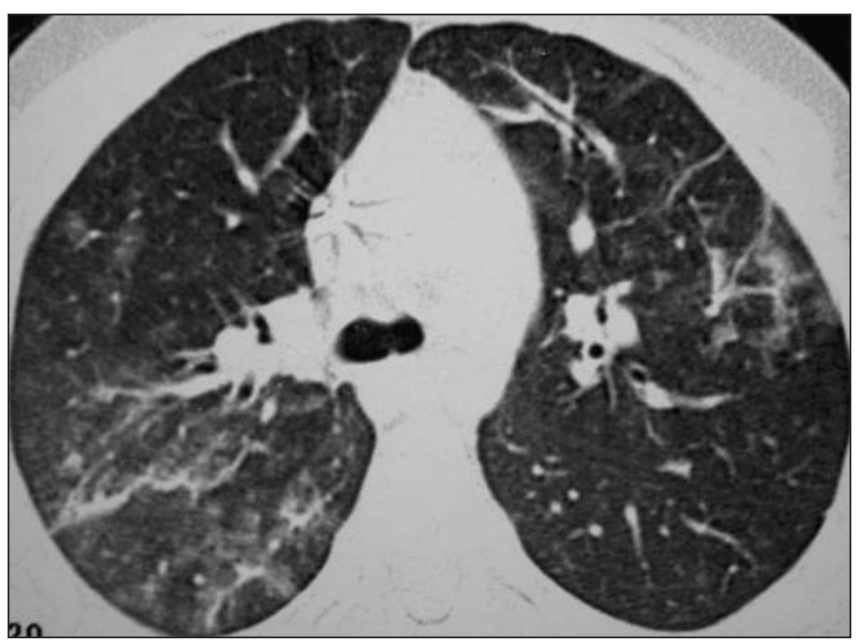

Figura 8. Corte de TCAR ao nível da carina revela áreas bilaterais de atenuação em vidro-fosco associadas a bandas parenquimatosas. Na evolução foi definido o diagnóstico de toxicidade a droga (bleomicina).

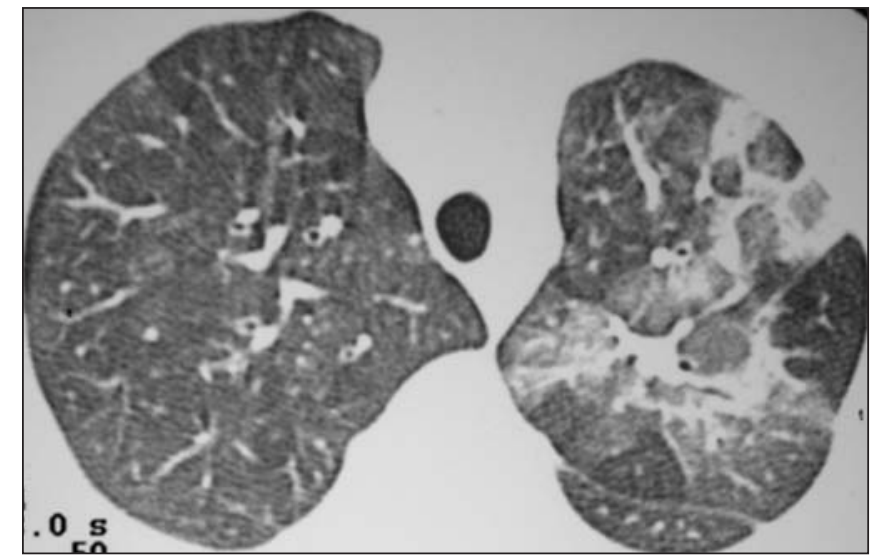

Figura 9. Corte de TCAR ao nível dos lobos superiores de um paciente com infecção por CMV, em que se observam áreas com atenuação em vidro-fosco difusas, mais evidentes à esquerda, sendo também identificados septos interlobulares espessados. 
adenovírus e picornavírus têm papel importante na etiologia de doenças respiratórias no pós-TMO ${ }^{(4)}$. Clinicamente, estes pacientes se apresentam com quadro de infecção das vias aéreas superiores, sendo que até $50 \%$ dos pacientes desenvolvem pneumonia na evolução. A incidência é maior no primeiro mês pós-TMO.

Há poucos trabalhos na literatura que descrevem os achados radiográficos em pacientes submetidos a TMO. Até $20 \%$ dos pacientes com pneumonia pelo VSR apresentam TCAR normal. Naqueles casos com alterações, os principais achados são pequenos nódulos centrolobulares, áreas de consolidação, opacidades em vidro-fosco, espessamento de paredes brônquicas e opacidades em árvore em brotamento (Figuras 11 e 12).

\section{Pneumonia por Pneumocystis carinii (PPC)}

A incidência de PPC tem diminuído com a instituição de profilaxia de rotina (trimetoprim/sulfametoxazol). Atualmente, a PPC é vista em menos de $10 \%$ dos pacientes submetidos a TMO, geralmente naqueles que não toleram a profilaxia ${ }^{(2)}$. $\mathrm{O}$ tempo médio de estabelecimento da doença é de dois meses pós-TMO. O Pneumocystis carinii pode ser diagnosticado quando a forma cística do organismo é identificada no LBA ou em biópsia com coloração de Grocott-Gomori.
As radiografias de tórax demonstram opacidades peri-hilares ou nos lobos superiores. As TCAR mostram áreas de atenuação em vidro-fosco, que podem ser difusas ou predominarem nas regiões peri-hilares ou em lobos superiores. Outro padrão descrito é a presença de um padrão em mosaico, poupando lóbulos pulmonares secundários adjacentes $^{(\mathbf{3 , 7})}$ (Figura 13).

\section{Pneumonia intersticial idiopática (PII)}

A PII ocorre em cerca de $12 \%$ dos pacientes submetidos a TMO, sendo definida como lesão pulmonar difusa que se manifesta na ausência de qualquer infecção, entre 40 e 50 dias após o TMO. É essencialmente um diagnóstico de exclusão. A

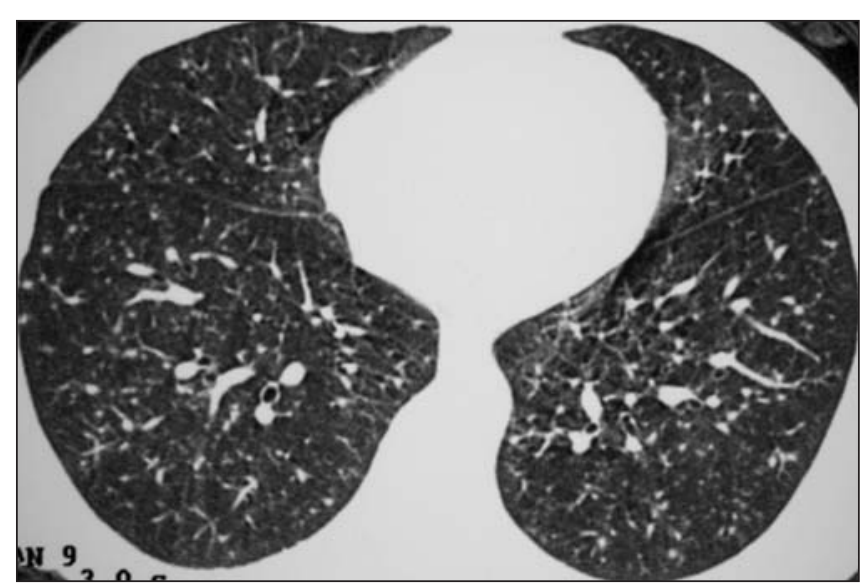

Figura 10. Corte de TCAR ao nível do terço inferior dos pulmões mostra múltiplos nódulos centrolobulares com dimensões inferiores a $5 \mathrm{~mm}$ de diâmetro. Neste paciente foi diagnosticada infecção por CMV.

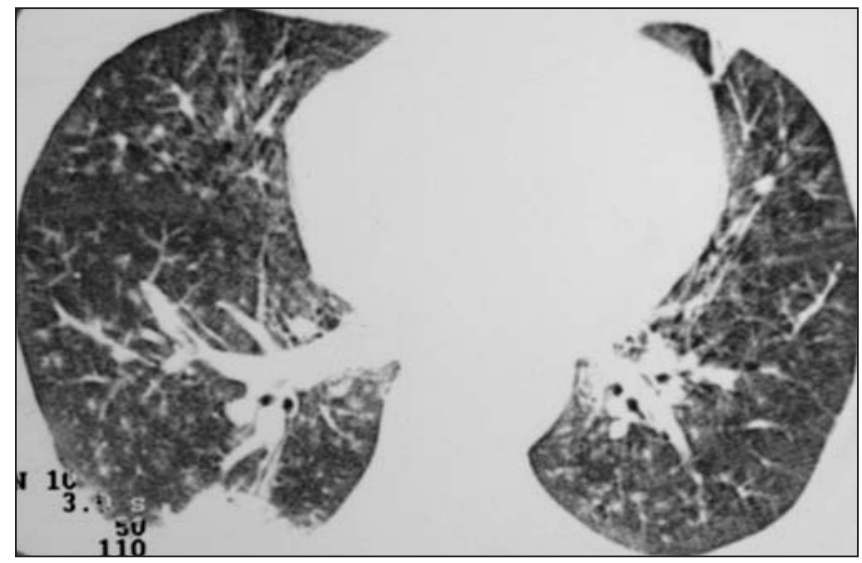

Figura 12. Corte de TCAR ao nível das bases pulmonares de um paciente com infecção por VSR mostra foco de consolidação subsegmentar em lobo inferior direito e opacidades nodulares centrolobulares com aspecto de "árvore em brotamento" nos lobos inferiores e médio.

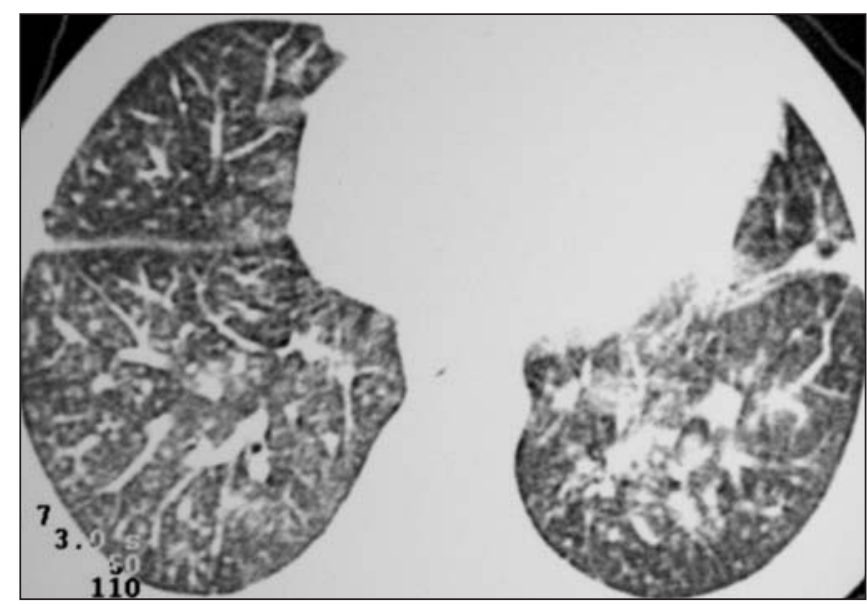

Figura 11. Corte de TCAR ao nível das bases pulmonares demonstra múltiplos nódulos centrolobulares. No lobo inferior esquerdo há também nódulos maiores, confluentes, e sinais de espessamento do interstício peribroncovascular. 0 diagnóstico de pneumonia pelo VSR foi definido através de LBA.

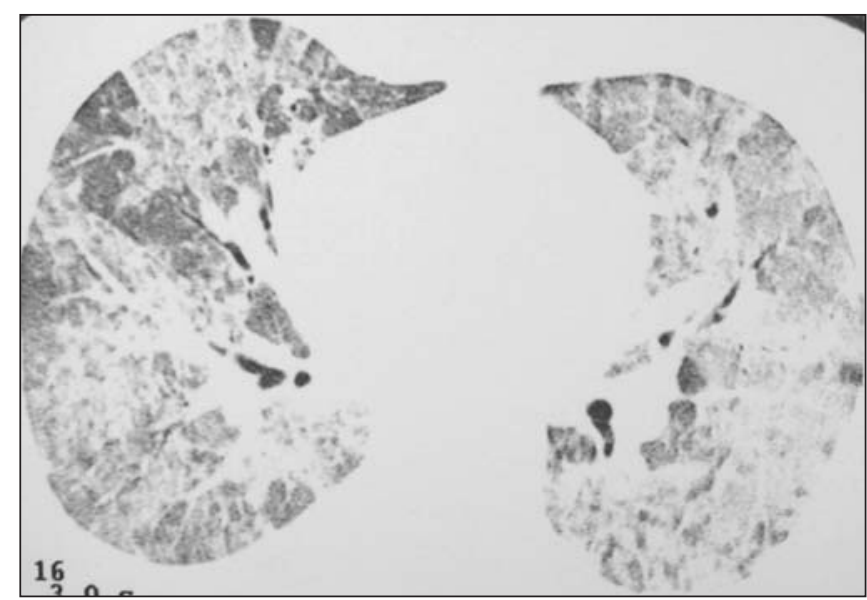

Figura 13. Corte de TCAR ao nível das pirâmides basais num paciente com pneumocistose demonstra áreas de atenuação em vidro-fosco difusas, espessamento de septos interlobulares e nódulos centrolobulares tendendo à confluência em lobo superior direito. 
causa parece estar relacionada à toxicidade durante o preparo pré-transplante ${ }^{(2)}$.

Os principais achados radiográficos e tomográficos são opacidades alveolares difusas ou multifocais, opacidades reticulares, espessamento de septos interlobulares e nódulos de vários tamanhos (Figura 14).

\section{FASE TARDIA}

Ocorre em um período após o $100^{\circ}$ dia pós-transplante, em que a função imune recuperou-se em grande parte, e as complicações são do tipo não infecciosas. Complicações pulmonares infecciosas ocorrem nesta fase quando os pacientes apresentam DECH ou falha na pega do enxerto.

\section{Bronquiolite obliterante (BO)}

Ocorre em até $10 \%$ dos pacientes pós$\mathrm{TMO}^{(7)}$, sendo rara em pacientes submetidos a TMO autólogo. Clinicamente desenvolve-se após o terceiro mês pós-TMO e os sintomas iniciais lembram infecção de via aérea superior. A etiologia é incerta e pacientes com DECH têm risco aumentado. Observa-se deterioração gradual das provas de função pulmonar e o diagnóstico é baseado na clínica e nestes exames. O diagnóstico é confirmado histologicamente nas amostras de biópsia de tecido pulmonar ${ }^{(2)}$.

Nas radiografias de tórax observa-se hiperinsuflação pulmonar na ausência de infiltrações. A TCAR revela dilatação brônquica e padrão de perfusão em mosaico, com evidência de aprisionamento de ar nos cortes em expiração ${ }^{(3,7)}$ (Figuras 15 e 16).

\section{Bronquiolite obliterante com pneumonia em organização}

A BOOP é uma complicação tardia em pacientes pós-TMO. As manifestações clínicas incluem tosse não produtiva, dispnéia e febre.

Os achados à TCAR incluem consolidações com distribuição subpleural ou peribrônquica, áreas de atenuação em vidro-fosco e pequenos nódulos. Os nódulos e as áreas de atenuação em vidro-fosco tendem a ser distribuídos aleatoriamente, e os nódulos em geral têm margens bem definidas $^{(3,7)}$ (Figura 17).

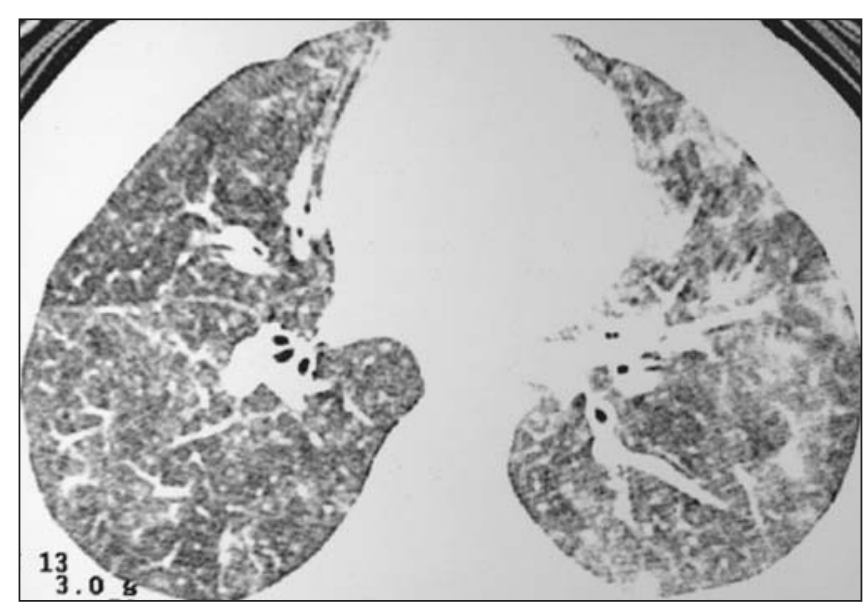

Figura 14. Corte de TCAR ao nível das pirâmides basais revela nódulos periféricos à esquerda e áreas de atenuação em vidro-fosco difusas. 0 diagnóstico de PII foi definido na evolução.

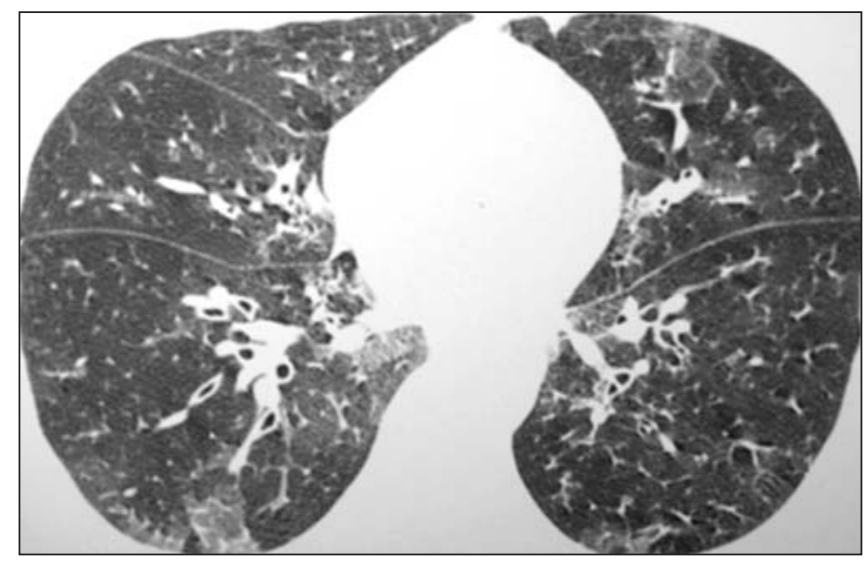

Figura 16. Corte de TCAR ao nível das veias pulmonares inferiores num paciente com BO revela discreto espessamento de septos inter e intralobulares e áreas de atenuação em vidro-fosco periféricas.

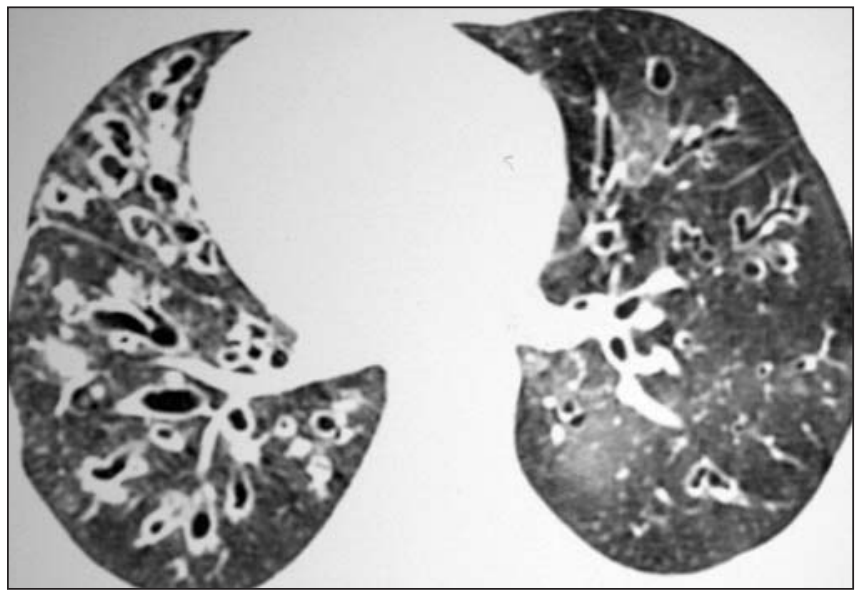

Figura 15. Corte de TCAR ao nível das veias pulmonares inferiores mostra áreas de redução da atenuação e vascularização pulmonar (perfusão em mosaico) e bronquiectasias císticas. A biópsia pulmonar definiu o diagnóstico de BO.

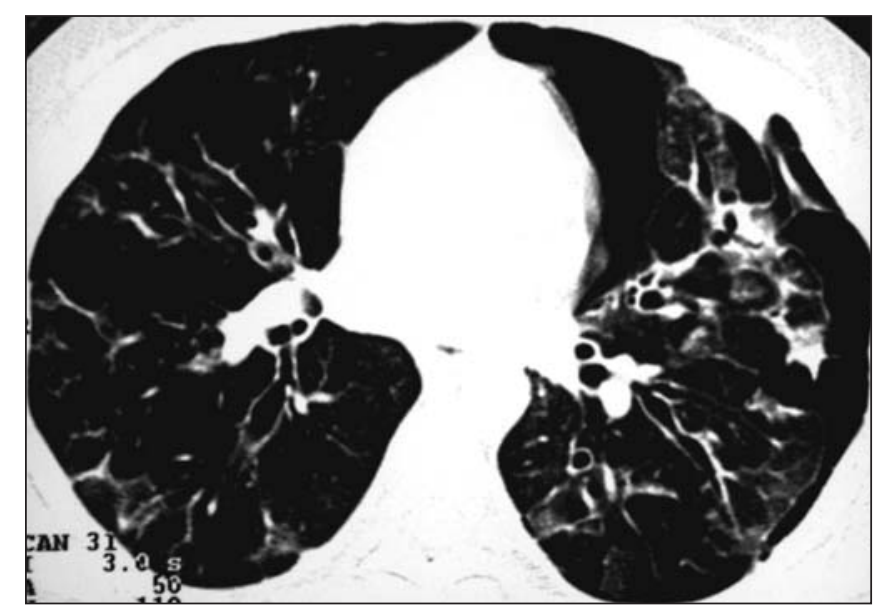

Figura 17. Corte de TCAR ao nível do lobo médio demonstra redução difusa da atenuação do parênquima pulmonar, associada a áreas de atenuação em vidrofosco e espessamento de septos interlobulares. Bronquiectasias císticas e varicosas, bem como pneumotórax à esquerda também são caracterizados. 0 diagnóstico de BOOP foi definido na evolução. 


\section{Doença do enxerto contra o hospedeiro} crônica

A DECH crônica resulta de uma reação imune de células doadoras imunocompetentes contra tecido de hospedeiro imunodeprimido. Ocorre em até 50\% dos pacientes que sobrevivem seis meses ou mais após o $\mathrm{TMO}^{(7)}$. Não tem manifestação pulmonar específica, sendo que as lesões pulmonares nestes pacientes são secundárias às alterações no sistema imune e incluem infecções por bactérias capsuladas, Aspergillus e Pneumocystis carinii, aspiração crônica, BO e pneumonia intersticial linfóide.

\section{CONCLUSÃO}

A TCAR é um excelente método para avaliação do parênquima pulmonar e pode ser útil no diagnóstico de doenças respiratórias em pacientes submetidos a TMO. Ressalte-se que os achados são isoladamente inespecíficos, porém, quando correlacionados com a clínica e a fase em que a anormalidade pulmonar ocorre, diminuise a lista de diagnósticos diferenciais. A TCAR é ferramenta adicional no auxílio da definição diagnóstica em um momento em que o quadro clínico do paciente pode deteriorar-se rapidamente, sendo necessária à instituição de terapêutica imediata.

\section{REFERÊNCIAS}

1. Krowka MJ, Rosenow EC III, Hoagland HC. Pulmonary complications of bone marrow transplantation. Chest 1985;87:237-246.

2. Soubani AO, Miller KB, Hassoun PM. Pulmonary complications of bone marrow transplantation. Chest 1996;109:1066-1077.
3. Worthy SA, Flint JD, Müller NL. Pulmonary complications after bone marrow transplantation: highresolution CT and pathologic findings. RadioGraphics 1997;17:1359-1371.

4. Whimbey E, Champlin RE, Couch RB, et al. Community respiratory virus infections among hospitalized adult bone marrow transplant recipients. Clin Infect Dis 1996;22:778-782.

5. Leung AN, Gosselin MV, Napper CH, et al. Pulmonary infections after bone marrow transplantation: clinical and radiographic findings. Radiology 1999;210:699-710.

6. Mori M, Galvin JR, Barloon TJ, Gingrich RD, Stanford W. Fungal pulmonary infections after bone marrow transplantation: evaluation with radiography and CT. Radiology 1991;178:721-726.

7. Wah TM, Moss HA, Robertson RJH, Barnard DL. Pulmonary complications following bone marrow transplantation. Br J Radiol 2003;76:373-379.

8. Kang EY, Patz EF Jr, Müller NL. Cytomegalovirus pneumonia in transplant patients: CT findings. J Comput Assist Tomogr 1996;20:295-299. 